\title{
Awareness and Practice of Proper Health Seeking Behaviour and Determinant of Self-Medication among Physicians and Nurses in a Tertiary Hospital in Southwest Nigeria
}

\author{
Kayode Rasaq Adewoye1, Shuaib Kayode Aremu2*, Tope Michael Ipinnimo ${ }^{3}$, \\ Idris Adedayo Salawu', Tesleem Olayinka Orewole ${ }^{5}$, Adewumi Bakare ${ }^{6}$ \\ ${ }^{1}$ Department of Community Medicine, Federal Teaching Hospital, Ido Ekiti/Afe Babalola University, Ado-Ekiti, Nigeria \\ ${ }^{2}$ ENT Department, Federal Teaching Hospital, Ido-Ekiti/Afe Babalola University, Ado-Ekiti, Nigeria \\ ${ }^{3}$ Department of Community Medicine, Federal Teaching Hospital, Ido Ekiti, Nigeria \\ ${ }^{4}$ Department of surgery, Federal Teaching Hospital, Ido-Ekiti, Nigeria \\ ${ }^{5}$ Department of Anesthesia, Federal Teaching Hospital, Ido-Ekiti/Afe Babalola University, Ado-Ekiti, Nigeria \\ ${ }^{6}$ Departments of Obstetrics and Gynecology, Federal Teaching Hospital, Ido-Ekiti/Afe Babalola University, Ado-Ekiti, Nigeria \\ Email: *shuaib.aremu@gmail.com
}

How to cite this paper: Adewoye, K.R., Aremu, S.K., Ipinnimo, T.M., Salawu, I.A., Orewole, T.O. and Bakare, A. (2019) Awareness and Practice of Proper Health Seeking Behaviour and Determinant of Self-Medication among Physicians and Nurses in a Tertiary Hospital in Southwest Nigeria. Open Journal of Epidemiology, 9, 36-49.

https://doi.org/10.4236/ojepi.2019.91004

Received: November 28, 2018

Accepted: January 8, 2019

Published: January 11, 2019

Copyright $\odot 2019$ by authors and Scientific Research Publishing Inc. This work is licensed under the Creative Commons Attribution International License (CC BY 4.0).

http://creativecommons.org/licenses/by/4.0/

CC) (i) Open Access

\begin{abstract}
Background: There is generally a lack of good health-seeking practices among health professionals due to a variety of factors, including the intensity of the medical practice itself. Doctors and nurses are perceived to have a good knowledge of ideal health-seeking behaviors and as such, it is important to determine the level of their awareness and estimate whether this knowledge is put into practice. This study, therefore, aimed to determine the level of awareness and practices of proper health-seeking behavior and to identify the factors responsible for self-medication among doctors and nurses in a tertiary hospital in Nigeria. Methodology: A cross-sectional descriptive study was conducted between April and may 2018 among 106 doctors and 164 nurses in a tertiary health facility in Ido-Ekiti, Ekiti State, Southwestern Nigeria. A simple random sampling technique by balloting was performed from the list of doctors and nurses in the hospital to select doctors and nurses that participated in the study. A pretested semi-structured self-administered questionnaire was designed and used to collect data. The data were entered into the computer software and analyzed using SPSS version 20. P $\leq 0.05$ was taken as significant. Result: Out of 106 doctors and 164 nurses recruited, only 102 doctors and 143 nurses filled the questionnaire completely and returned for analysis. One hundred and four respondents (42.4\%) fall within the ages of 31 - 40 years with a male to female ratio of 1:1.23. Awareness of proper health
\end{abstract}


seeking behavior among both doctors and nurses was high among the two groups with no statistically significant difference between them. Twenty-nine (28.0\%) doctors compared with thirty-four $(23.8 \%)$ nurses go for a regular medical check-up with no statistically significant difference between the two groups $(\mathrm{p}=0.411)$. Out of these, $5(17.2 \%)$ doctors and $7(23.8 \%)$ nurses visit at an interval of less than 6 month $(\mathrm{p}=0.736)$. There is a statistically significant difference in the number of doctors $(60.8 \%)$ compared with nurses $(41.3 \%)$ that have consulted a doctor in the last one year $(\mathrm{p}=0.003)$. More than half $(51.6 \%)$ of this consultation among doctors was over the phone whereas $64.4 \%$ of such among nurses were via clinic appointment $(\mathrm{p}=0.008)$. More doctors (90.2\%) comply with their treatment prescription from physicians compared with nurses $(77.6 \%)(\mathrm{p}=0.010)$. More nurses compared with doctors self-medicate when ill [Doctor 61.8\% (63), Nurses 78.3\% (112)] ( $\mathrm{p}=$ 0.005) and had also self-medicated in the last one year [Doctor $34.3 \%$ (35), Nurses $42.7 \%(61)](p=0.187)$. Decreasing age, decreasing years of experience, increasing working hours, lack of health insurance, fear of confidentiality and lack of satisfaction with health services are factors that significantly increased the likelihood of self-medication among doctors and nurses within the last one year. Conclusion: Awareness of proper health seeking behavior was high but this did not translate into proper health-seeking practices among doctors and nurses. There is apathy for regular medical check-up and self-medication was also high among this group of health workers. Decreasing age and years of experience, increasing working hours, lack of health insurance, fear of confidentiality and lack of satisfaction with health services were factors were identified to significantly increase the likelihood of self-medication.

\section{Keywords}

Health Seeking Behavior, Self-Medication, Awareness, Doctors, Nurses

\section{Introduction}

Doctors and nurses form an integral part of the human resource for health and this health workforce forms the backbone of any health system making them important to delivering quality healthcare. To enable them to deliver quality health care, it is important that they maintain a good standard of health. The quality of health care depends on the capability of the healthcare worker and the abilities of a health care worker will depend largely on his status of health. Healthcare workers are on a daily basis exposed to a myriad of occupational and safety hazards which when coupled with the stress of their enormous workload, predispose them to a wide variety of diseases [1]. They are also exposed to resistant strains of a variety of microbes known to be resident in hospital environments, making them susceptible to severe and difficult to treat illnesses [2]. It is also noticed that they are often busy with patients care and professional training to leave them with little or no time to take care of other aspects of life including 
seeking healthcare.

Health care seeking behaviors refer to actions by a person in the setting of perceived illness for the purpose of finding an appropriate solution. They involve attitudes or actions adopted during actual or potential illnesses, and the behavior of healthy individuals towards prevention of illness (Primary prevention), early diagnosis and treatment of already contracted illnesses (Secondary prevention) and forestalling complications associated with already established disease (Tertiary prevention) [3]. Health workers are at a higher risk of avoiding health-seeking behavior because they believe they are aware of the diseases and their symptoms as well as the pharmaceutical management of the disease [4]. They are also involved in informal mode of consultation (such as on corridors, in cars, over the phone etc.) which may take place without full history and proper examination thereby leading to wrong diagnosis, inadequate quality of care, defective treatment, and worsening of illness [2].

A study in Pakistan revealed that doctors had a greater access and were utilizing healthcare services more often compared to nurses $(p<0.001)$ [4]. Nurses were also less aware of the significance of regular health check-ups compared to doctor $(p<0.001)$ [4]. Another study in Israel showed that although doctors believed strongly in screening tests, only about $27.5 \%$ of respondents had undergone testing [5]. In Nigeria, Fawibe et al., carried out a study on medical care seeking behaviors of doctors in Kwara State, Nigeria. The result showed that $80.5 \%$ of Nigerian doctors reported one form of illness or the other in the last one year preceding the study and only $35 \%$ of them reportedly consulted another doctor. Majority (61.2\%) of this consultations were informal, such as over the phone consultation (45.6\%), corridor consultation (33.3\%) and home visit (21.1\%) and only about $18 \%$ of the consultation occurred within $24 \mathrm{hrs}$ of the illness [2]. Studies done in different part of the world have showed that self-medication was the commonest form of care among health care workers [4] [6].

Doctors and nurses are expected to be aware of the regulations guiding self-care in their various countries, as their various regulatory bodies have ethical codes put in place to guide these behaviors. American Medical Association Code of Medical Ethics, International Council of Nurses Code of Ethics and Code of Medical Ethics for the Nigerian Medical Association which states that "a doctor should avoid self-treatment and self- medication unless the illness is clearly minor or there is no access to a colleague" [7] are some of these ethical codes. Nurses (20\%) were less aware of the organization policies offered for employees ill-health compared to doctors $(44 \%)(p<0.001)$ [4]. On self-prescription practices, Fadare J and Desalu showed that $96.2 \%$ of Nigerian doctors practiced self-medication, and $70.5 \%$ had informally asked colleagues for a prescription [8].

Some of the reasons offered for self-medication includes; familiarity with treatment options, less time consumption, quick relief, less severity of the condition, cost etc. [4]. In addition to the determinants (predisposing, enabling, and 
hindering) that affect health-seeking behaviour among the general population, those exclusive to health workers include: time pressure; fear of showing weakness or lack of knowledge; and concerns about confidentiality [2]. Studies have shown that females are more likely to consult physician than males [9] [10]. There is generally a lack of good health practice among health professionals due to a variety of factors, including the intensity of the medical practice itself. They are perceived to have a good knowledge of ideal health-seeking behaviors and as such, it is important to determine the level of their awareness and estimate whether this knowledge is put into practice. This study, therefore, aimed to determine the level of awareness and practices of proper health seeking behavior among doctors and nurses and identify the factors responsible for self-medication among them. This study will assist policy making that will help improve health seeking behavior among physicians and nurses. Data obtained from this study will provide more literature to health-seeking behavior and also serve as a reference for further study.

\section{Methodology}

A descriptive cross-sectional study which was conducted between April and May 2018 in Federal Teaching Hospital Ido-Ekiti, Ekiti State, South West region of Nigeria. The hospital was established in the year 1954 as a general hospital but was changed to Federal Medical Centre in the year 1998 and later to a teaching hospital by 2014 for the training of medical students. It serves as the referral center for all other health institutions in the state and environs. The hospital comprises about 300 beds, 260 Medical doctors, 400 Nurses, 14 Pharmacist, 4 Pharmacy technicians, 18 Laboratory scientist, and 500 Ward attendants.

The study population included Medical Doctors and Nurses in Federal Teaching Hospital Ido-Ekiti, with a total population of 660 . This study included Medical Doctors and Nurses of all ages and both sexes working at the hospital and willing to participate in the study and excluded doctors and nurses that decline taking part as well as those that were unavailable (leave, outside positing and sick leave).

A minimum sample size was calculated using the formula for cross-sectional study [11]

$$
N=\frac{Z^{2} p q}{d^{2}}
$$

and

$$
N_{f}=\frac{n}{1+n / N}
$$

For a population that is less than 10,000 .

Prevalence of existing practice of health seeking behavior of healthcare workers was assumed at $50 \%$ and a bound on the error of $\pm 5 \%$, precision level of 0.5 and confidence level of $95 \%$. An upward adjustment for $10 \%$ to account for non-response and inappropriate entries, gave a sample size of 270 doctors and 
nurses for this study.

The number of Doctors (106) and Nurses (164) recruited for the study were determined by proportionate allocation followed by systematic random sampling to select 106 Doctors from the total number of Doctors in the hospital which were 260 and likewise to select 164 Nurses from the total number of nurses which were 400 . The participants were followed in their respective departments (workplace) during morning and afternoon shifts. The Physicians and the nurses on annual leave, maternity leave or any other form of leave or on outside posting or not willing to participate in the study were excluded from the study.

A semi-structured self-administered questionnaire was designed and used to collect data. The Questionnaire comprises of four sections: Section A: Socio-demographic Information, Section B: Awareness on Proper Health Seeking Behaviour, Section C: Current Health Seeking Practices among health workers, Section D: Factors affecting self-medication. A Pre-test of the questionnaire was done at Ekiti State University Teaching Hospital to test for its viability and reliability using 10 percent of sample size.

The data was entered into the computer software analyzed using SPSS version 20. Descriptive statistics were presented using frequency tables and charts. Quantitative variables such as age were summarized as mean and standard deviation. Pearson chi-square was used to compare two variables and level of significance was set at $5 \%$.

The ethical clearance was obtained from the Federal teaching hospital Ido-Ekiti (FETHI) research ethics committee. The aim of the study was explained to the participants, and an informed consent of each willing participant was sought and obtained. Confidentiality and anonymity were maintained.

\section{Result}

The sociodemographic characteristic of the respondents is shown in Table 1. Out of 106 doctors and 164 nurses recruited, only 102 doctors and 143 nurses filled the questionnaire completely and returned for analysis, giving a total of 245 questionnaires that were analyzed. This represents a respondent rate of $90.7 \%$. Almost half of the respondents 104 (42\%) fall between the ages of 31 and 40 years. The male to female ratio was 1:1.23, male $44.9 \%$ (110), and female $55.1 \%$ (135). About half of respondents were married and majorities are Christian.

Most work more than forty hours per week (81.7\%) and 55.5\% of the respondents had less than ten years of experience.

Using all the parameters on Table 2, it was revealed that the awareness of proper health seeking behavior among both doctors and nurses was high. Awareness was generally higher among doctors in terms of regular medical check-up [Doctors $98.0 \%$ (100), Nurses $94.4 \%$ (135)], consulting a doctor formally [Doctor 97.1\% (99), Nurses $92.3 \%$ (132)], adhering strictly to physician prescription [Doctors $92.2 \%$ (94), Nurses $87.4 \%$ (125)] and not self-medicating 
Table 1. Socio-demographic characteristics of respondents.

\begin{tabular}{|c|c|c|}
\hline Variable & $\begin{array}{c}\text { Frequency } \\
n=245\end{array}$ & $\begin{array}{c}\text { Percent } \\
(\%)\end{array}$ \\
\hline \multicolumn{3}{|l|}{ Gender } \\
\hline Male & 110 & 44.9 \\
\hline Female & 135 & 55.1 \\
\hline \multicolumn{3}{|l|}{ Age } \\
\hline Below 20 & 25 & 10.2 \\
\hline $21-30$ & 46 & 18.8 \\
\hline $31-40$ & 104 & 42.4 \\
\hline $41-50$ & 52 & 21.2 \\
\hline Above 50 & 18 & 7.3 \\
\hline \multicolumn{3}{|l|}{ Marital Status } \\
\hline Single & 47 & 19.2 \\
\hline Married & 127 & 51.8 \\
\hline Divorced & 71 & 29.0 \\
\hline \multicolumn{3}{|l|}{ Religion } \\
\hline Christian & 156 & 63.7 \\
\hline Islam & 89 & 36.3 \\
\hline \multicolumn{3}{|l|}{ Occupation } \\
\hline Nurse & 143 & 58.4 \\
\hline Doctor & 102 & 41.6 \\
\hline \multicolumn{3}{|l|}{ Years of Experience } \\
\hline$<10$ & 136 & 55.5 \\
\hline $11-20$ & 92 & 37.6 \\
\hline$>20$ & 17 & 6.9 \\
\hline \multicolumn{3}{|c|}{ Working Hours Per Week } \\
\hline$<40 \mathrm{hrs}$ & 45 & 18.4 \\
\hline $41-60 \mathrm{hrs}$ & 130 & 53.1 \\
\hline$>60 \mathrm{hrs}$ & 70 & 28.6 \\
\hline
\end{tabular}

Table 2. Awareness of Proper Health Seeking Behaviour (PHSB).

\begin{tabular}{|c|c|c|c|}
\hline Variable & $\begin{array}{c}\text { Doctors } \\
\text { n (\%) } \\
\mathrm{N}=102\end{array}$ & $\begin{array}{c}\text { Nurses } \\
\text { n (\%) } \\
N=143\end{array}$ & p-value \\
\hline \multicolumn{4}{|c|}{ Awareness that regular medical check-up is a PHSB } \\
\hline Yes & $100(98.0)$ & $135(94.4)$ & 0.156 \\
\hline No & $2(2.0)$ & $8(5.6)$ & \\
\hline \multicolumn{4}{|c|}{$\begin{array}{l}\text { Awareness that periodic screening for certain } \\
\text { diseases is a PHSB }\end{array}$} \\
\hline Yes & $92(90.2)$ & $133(93.0)$ & 0.428 \\
\hline No & $10(9.8)$ & $10(7.0)$ & \\
\hline
\end{tabular}




\section{Continued}

\begin{tabular}{|c|c|c|c|}
\hline \multicolumn{4}{|c|}{$\begin{array}{l}\text { Awareness that consulting a doctor formally } \\
\text { when you are ill is a PHSB }\end{array}$} \\
\hline Yes & $99(97.1)$ & $132(92.3)$ & 0.114 \\
\hline No & $3(2.9)$ & $11(7.7)$ & \\
\hline \multicolumn{4}{|c|}{$\begin{array}{l}\text { Awareness that adhering strictly to doctor's prescription } \\
\text { is a PHSB }\end{array}$} \\
\hline Yes & $94(92.2)$ & $125(87.4)$ & 0.235 \\
\hline No & $8(7.8)$ & $18(12.6)$ & \\
\hline \multicolumn{4}{|c|}{ Awareness that not self-medicating when ill is a PHSB } \\
\hline Yes & $97(95.1)$ & $126(88.1)$ & 0.059 \\
\hline No & $5(4.9)$ & $17(11.9)$ & \\
\hline
\end{tabular}

when ill [Doctor 95.1\% (97), Nurses $88.1 \%$ (126)] with the exception of awareness of periodic screening for certain diseases which was higher among nurses [Doctors $90.2 \%$ (92), Nurses $93.0 \%$ (133)]. None of these is statistically significant.

Table 3 shows health seeking practice of the respondent. Less than a third of respondents go for regular medical check-up. Twenty nine (28.0\%) doctors compared with thirty four (23.8\%) nurses go for regular medical check-up ( $\mathrm{p}=$ $0.411)$. Out of these, 5 (17.2\%) doctors and $7(23.8 \%)$ nurses visits at an interval of less than 6month ( $\mathrm{p}=0.736)$. When asked about what is done first when ill, $54.9 \%$ of (56) doctors and $37.8 \%$ of (54) nurses consult a doctor. Other respondents self-medicate [Doctors $20.6 \%$ (21), Nurses $30.1 \%$ (43)], pray/seek supernatural healing [Doctor 13.7\% (14), Nurses14.7\% (21)], take herbs/visit a traditional healer [Doctor 1\% (1), Nurses 2.1\% (3)] or do nothing [Doctor 9.8\% (10), Nurses $15.4 \%(22)](\mathrm{p}=0.100)$.

There is a statistically significant difference in the number of doctors (60.8\%) compared with nurses (41.3\%) that have consulted a doctor in the last one year $(\mathrm{p}=0.003)$. More than half $(51.6 \%)$ of this consultation among doctors was over the phone whereas $64.4 \%$ of such among nurses was via clinic appointment ( $\mathrm{p}=$ 0.008 ).

More doctors (90.2\%) comply with their treatment prescription from physicians compared with nurses $(77.6 \%)(\mathrm{p}=0.010)$. Self-medication was equally common in the two groups. More nurses compared with doctors self-medicate when ill [Doctor 61.8\% (63), Nurses 78.3\% (112)] $(\mathrm{p}=0.005)$ and had also self-medicated in the last one year [Doctor 34.3\% (35), Nurses 42.7\% (61)] ( $\mathrm{p}=$ $0.187)$. However, when asked the duration of self-medication before taking next action, it was revealed that more nurses self-medicate for shorter duration i.e. 1 2 weeks [Doctors 47.6\% (30), Nurses 68.6\% (78)] and also more nurse self-medicate and stop immediately the symptom get severe or subsidies [Doctors $3.2 \%$ (2), Nurse $5.4 \%(6)$ ] ( $\mathrm{p}=0.001)$.

Table 4 explored the factors associated with self-medication in the last one 
Table 3. Proper health seeking practice.

\begin{tabular}{|c|c|c|c|}
\hline Variable & $\begin{array}{c}\text { Doctors } \\
\text { n (\%) } \\
N=102\end{array}$ & $\begin{array}{c}\text { Nurses } \\
\text { n (\%) } \\
N=143\end{array}$ & p-value \\
\hline \multicolumn{4}{|l|}{ Go for a regular medical check-up } \\
\hline Yes & $29(28.4)$ & $34(23.8)$ & 0.411 \\
\hline No & $73(71.6)$ & $109(76.2)$ & \\
\hline \multicolumn{4}{|l|}{ If yes, how often } \\
\hline$<6$ monthly & $5(17.2)$ & $7(23.8)$ & 0.736 \\
\hline$>6$ monthly & $24(82.8)$ & $27(79.4)$ & \\
\hline \multicolumn{4}{|l|}{ What is done first when ill } \\
\hline Nothing & $10(9.8)$ & $22(15.4)$ & 0.100 \\
\hline Take herbal medication/visit a traditional healer & $1(1.0)$ & $3(2.1)$ & \\
\hline Pray/seek supernatural healing & $14(13.7)$ & $21(14.7)$ & \\
\hline Self-medicate & $21(20.6)$ & $43(30.1)$ & \\
\hline Consult a doctor & $56(54.9)$ & $54(37.8)$ & \\
\hline \multicolumn{4}{|l|}{ Ever consulted a doctor in the last one year } \\
\hline Yes & $62(60.8)$ & $59(41.3)$ & 0.003 \\
\hline No & $40(39.2)$ & $84(58.7)$ & \\
\hline \multicolumn{4}{|l|}{ Mode of consultation if ever consulted a doctor } \\
\hline Clinic appointment & $23(37.1)$ & $38(64.4)$ & 0.008 \\
\hline Over the phone & $32(51.6)$ & $19(32.2)$ & \\
\hline At home & $7(11.3)$ & $2(3.4)$ & \\
\hline \multicolumn{4}{|l|}{ Comply with your treatment prescription from doctors } \\
\hline Yes & $92(90.2)$ & $111(77.6)$ & 0.010 \\
\hline No & $10(9.8)$ & $32(22.4)$ & \\
\hline \multicolumn{4}{|l|}{ Self-medication when ill } \\
\hline Yes & $63(61.8)$ & $112(78.3)$ & 0.005 \\
\hline No & $39(38.2)$ & $31(21.7)$ & \\
\hline \multicolumn{4}{|l|}{ Length of time for self-medication before next action } \\
\hline 1 - 2 weeks & $30(47.6)$ & $78(68.6)$ & 0.001 \\
\hline 3 - 4 weeks & $20(31.7)$ & $25(22.3)$ & \\
\hline$>4$ weeks & $11(17.5)$ & $3(2.7)$ & \\
\hline Till symptom subsides or get severe & $2(3.2)$ & $6(5.4)$ & \\
\hline \multicolumn{4}{|l|}{ Ever self-medicated in the last one year } \\
\hline Yes & $35(34.3)$ & $61(42.7)$ & 0.187 \\
\hline No & $67(65.7)$ & $82(57.3)$ & \\
\hline
\end{tabular}


Table 4. Factors associated with self-medication in the last one year.

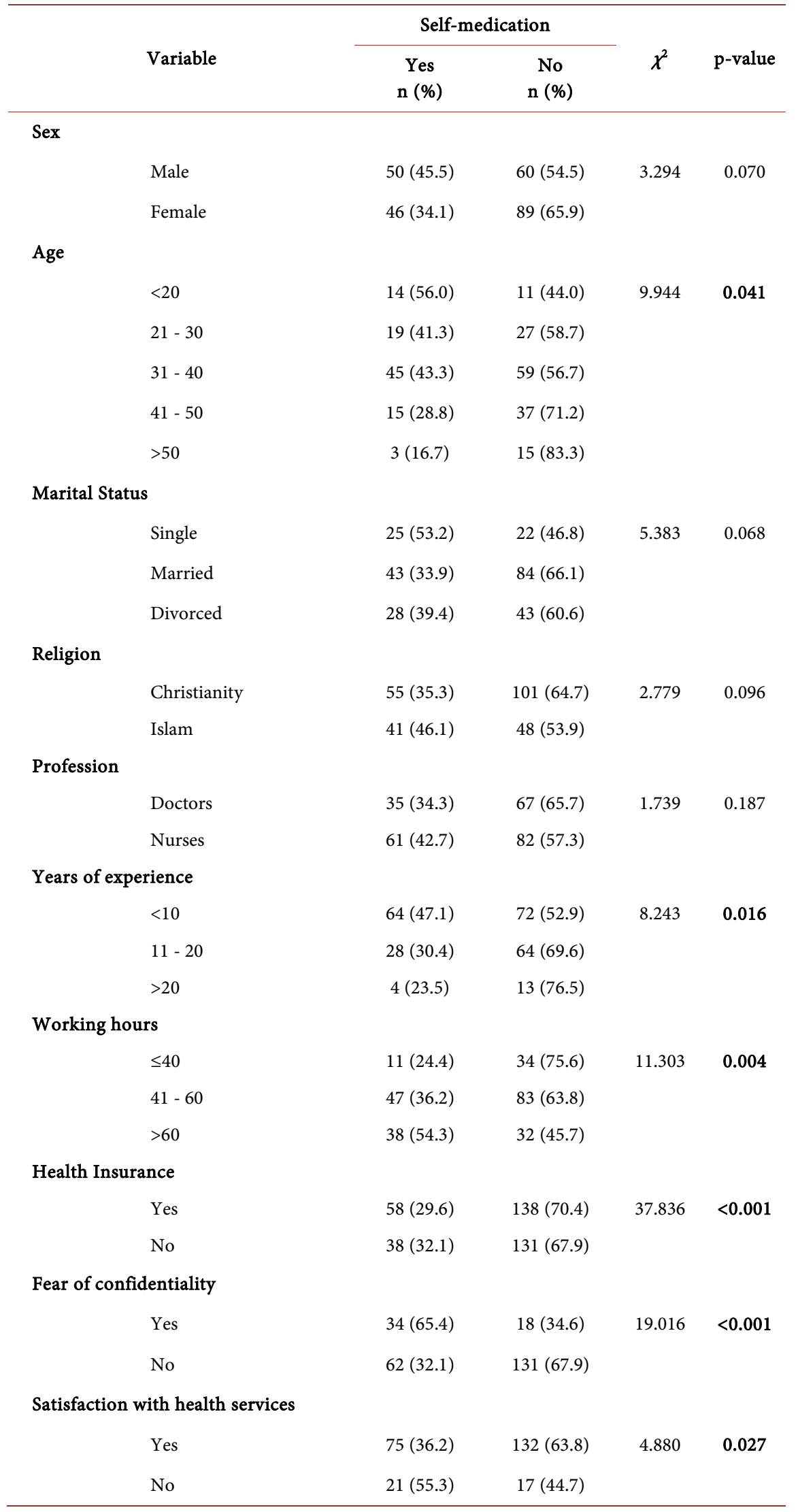


year. It was revealed that the likelihood that a respondent (doctors and nurses) will self-medicate depends on age, years of experience, working hours, health insurance, confidentiality and satisfaction with health services. Decreasing age, decreasing years of experience, increasing working hours, lack of health insurance, fear of confidentiality and lack of satisfaction with health services are factors that will significantly increase the likelihood of self-medication among respondents in the last one year. Male gender and being single is also found to increase the likelihood of self-medication in the last one year, though these two were not statistically significant.

\section{Discussion}

The aim of this study was to determine the level of awareness and practices of proper health-seeking behavior and to identify the factors responsible for self-medication among doctors and nurses in federal teaching hospital Ido-Ekiti. The result from this study showed a high level of awareness of proper health seeking behavior among doctors and nurses. Comparing levels of awareness between doctors and nurse didn't show any statistically significant difference. There are limited studies on the awareness of proper health seeking behavior among these categories of health workers. This high level of awareness might be due to training they went through before becoming professionals.

Despite this high level of awareness, it is however worrisome that not up to $30 \%$ of them go for regular medical check-up. This is consistent with the study among family doctors by Peleg et al. who found that family doctors had a strong belief in periodic check-ups but these beliefs did not translate into personal uptake [5]. This low level of practice of regular medical check-up may be due to the busy schedule of doctors and nurses which may not permit them with enough time to go for regular check-ups. Another reason may be due to the absence of policies enforcing health workers to go for regular medical check-up. Fear of confidentiality could also be a reason for the low level of regular medical check-up among doctors and nurses as they may not be comfortable disclosing their health status to their colleagues. A regular medical checkup is an important measure in the prevention especially the secondary prevention of diseases. Having a healthy human resource for health will help increase access and subsequently improve the overall health system [12].

There was a statistically significant difference in the number of doctors consulting a physician than nurses in the last one year. This may be because of the personal relationship among doctors as a lot of the doctor's consultations are usually informal i.e. over the phone, unlike the nurses who wait to consult the physician through the right channel via clinic appointment.

Self-medication was high in this study among the respondents. Though a higher value of $98.6 \%$ was gotten among physicians in a study done in another part of the country [13]. This is also similar to results gotten from other parts of the world [4] [14] [15]. Studies done among students of colleges of health sciences by Ehigiator et al. in Benin and Bekele et al. in Ethiopia also revealed 
similar results where $76.8 \%$ and $77.1 \%$ of students self-medicate respectively [16] [17]. The practice of self-medication among health workers is probably not picked up from practice or experience, it must have been developed while in school or even before they got into school. Incorporating health education against self-medication into medical and nursing school curriculum may help to reduce the magnitude of this menace among doctors and nurses.

Self-medication was significantly higher among nurses than doctors. This result differs from the report of Bana and colleagues among Pakistani doctors and nurses that show no significant difference in the prevalence of self-medication among these two groups of the health professional [4]. The lower prevalence of self-medication among doctors may be due to the personal relationship among doctors which makes consultations including informal consultations easier for them than nurses at any point in time. The high awareness of "not self-medicating when ill as a proper health seeking behavior" among doctor compared with nurses (though not statistically significant) may also account for the lower prevalence of self-medication among doctors. Among the respondents that self-medicate, the duration of self-medication significantly differs between doctors and nurses. The result from this study shows that doctors self-medicate longer than nurses, this also contrasts the findings among Pakistani doctors and nurses where doctors self-medicate for a shorter duration compared with nurses [4]. Doctors self-medicating longer than nurses may be due to their knowledge of pharmacology and the need to complete a course of drug regimen before switching to another.

Another finding in this study is the identification of factors associated with self-medication among respondents in the last one year. Self-medication in the last one year was used to minimize the effect of recall bias. Decreasing age and years of experience, increasing working hours, lack of health insurance, fear of confidentiality and lack of satisfaction with health services were factors identified to significantly increase the likelihood of self-medication within the last one year among doctors and nurses. Previous studies, however, contrast this finding where the year of clinical experience did not significantly affect the likelihood of self-medication [13] [18]. Some of the reasons for self-medication found in other studies were previous experience with the illness [16] [19], perceived minor nature of the illness [16] [17] [19], poor quality of routine health care services [17] and that it saves time [17].

The older respondents will most likely have more years of clinical experience. This experience includes but is not limited to the rational use of a drug which may likely affect their self-medication practice, thus reducing the likelihood of self-medication in them. A study in Pakistan showed that practice of safe practices was more prevalent among healthcare whose working experience is more than five years [20]. Respondents with higher working hours will have little or no time for proper medical consultation and will most likely result into self-medication when ill. Health insurance helps to protect against the risk of catastrophic health expenditure and has helped improved financial access and 
utilization of health services. Therefore doctors and nurses on health insurance will prefer to consult a physician normally so as to reduce the financial burden of their treatment thereby reducing self-medication in them. People generally are more confident, secure and also satisfied when their confidentiality is preserved. Respondents will tend to consult a physician and not self-medicate if they have confidence and satisfaction in the health services.

This study is not without limitation. Though the history of self-medication in the last one year was used to determine factors associated with self-medication, this will only reduce and not totally abolishes the effect of recall bias. The study is also carried out in a tertiary hospital setting which may not show the total picture of all doctors and nurses who work in a private hospital and other levels of care.

\section{Conclusions}

This study provides valuable information on health-seeking behavior and self-medication among doctors and nurses in Nigeria. Awareness of proper health seeking behavior was high but this did not translate into proper health-seeking practices among doctors and nurses. There is apathy for regular medical check-up and self-medication was also high among this group of health workers. Decreasing age and years of experience, increasing working hours, lack of health insurance, fear of confidentiality and lack of satisfaction with health services were factors seen to significantly increase the likelihood of self-medication.

It will, therefore, be noteworthy if policies and measure are instituted to improve regular medical check-up among doctors and nurses in order to prevent diseases in them. Health educating the younger doctors and nurses and those with lesser years of clinical practice on the significance of stopping self-medication will go a long way in curbing this menace. Getting every doctors and nurse on health insurance scheme coupled with reducing their workload and giving them time off to consult a physician when they are ill will help reduce self-medication among them. Lastly, the government needs to improve the health system especially in the line of satisfaction with the health services. All these will go a long way in reducing the prevalence of self-medication among doctors and nurses.

\section{Conflicts of Interest}

The authors declare no conflicts of interest regarding the publication of this paper.

\section{References}

[1] WHO/Health Workers (2017) Health Worker Occupational Health. https://www.who.int/occupational_health/en/

[2] Fawibe, A.E., Odegiah, I.O., Akande, T.M., Saludeen, A.G. and Olanrewaju, I. (2017) Self-Reported Medical Care Seeking Behavior of Doctors in Nigeria. Alexandria Journal of Medicine, 53, 117-122. https://doi.org/10.1016/j.ajme.2016.04.003 
[3] Kay, M.P., Mitchell, G.K. and Del Mar, C.B. (2004) Doctors Do Not Look after Their Own Physical Health. Medical Journal of Australia, 181, 368-370.

[4] Bana, S., Yakoob, J., Jivany, N., Faisal, A., Jawed, H. and Awan, S. (2016) Understanding Health Seeking Behavior of Health Care Professionals in Tertiary Care Hospitals in Pakistan. Journal of Ayub Medical College, Abbottabad, 28, 545-549.

[5] Preleg, R., et al. (2013) Screening Test among Family Doctors "Do We Do as We Preach?” Public Health, 127, 282-289. https://doi.org/10.1016/j.puhe.2012.12.010

[6] Aluko, O.O., Adebayo, A.E. and Popoola, B.F. (2016) Knowledge, Attitudes, and Perceptions of Occupational Hazards and Safety Practices in Nigerian Healthcare Workers. BMC Research Notes, 9, 71. https://doi.org/10.1186/s13104-016-1880-2

[7] Medical and Dental Council of Nigeria (1995) Section A. 13, Self-Medication by Registered Practitioners. In: Rules of Professional Conduct for Medical and Dental Practitioners.

[8] Fadare, J. and Desalu, O. (2014) Self-Prescription by Nigerian Medical Doctors. South African Family Practice, 56, 253-257. https://doi.org/10.1080/20786190.2014.980155

[9] Pullen, D., Lonic, C.E., Lyle, D.M., et al. (1995) Medical Care of a Doctor. Medical Journal of Australia, 162, 481-484.

[10] Thompson, A.E., Anisimowicz, Y., Miedema, B., Hogg, W., Wodchis, W.P. and and Aubrey-Bassler, K. (2016) The Influence of Gender and Other Patients Characteristics on Health Care-Seeking Behavior: A QUALICOPC Study. BMC Family Practice, 17, 38. https://doi.org/10.1186/s12875-016-0440-0

[11] Araoye, M.O. (2004) Research Methodology with Statistics for Health and Social Sciences. Nathadex Publishers, Ilorin.

[12] World Health Organization (2018) Human Resources for Health. http://www.wpro.who.int/topics/human_resources_health/en

[13] Agaba, P.A., Ocheke, A.N., Akanbi, M.O., Daniyam, C.A., Ugoya, S.O., Okeke, E.N., et al. (2011) Health Seeking Behavior of Physicians at the Jos University Teaching Hospital. Nigerian Medical Journal, 52, 90-94.

[14] Chen, J.Y., Tse, E.Y.Y., Lam, T.P., Li, D.K.T., Chao, D.V.K. and Kwan, C.W. (2008) Doctors' Personal Health Care Choices: A Cross-Sectional Survey in a Mixed Public/Private Setting. BMC Public Health, 8, 183. https://doi.org/10.1186/1471-2458-8-183

[15] Rosvold, E.O. and Bjertness, E. (2002) Illness Behavior among Norwegian Physicians. Scand Journal of Public Health, 1, 125-132. https://doi.org/10.1080/14034940210133744

[16] Ehigiator, O., Azodo, C.C., Ehizele, A.O., Ezeja, E.B., Ehigiator, L. and Madukwe, I.U. (2013) Self-Medication Practices among Dental, Midwifery and Nursing Students. European Journal of General Dentistry, 2, 54-57. https://doi.org/10.4103/2278-9626.106813

[17] Bekele, S.A., Argaw, M.D. and Yalew, A.W. (2016) Magnitude and a Factor Associated with Self-Medication Practices among University Students: The Case of Arsi University, College of Health Science, Asenlla, Ethiopia: Cross-Sectional Survey-Based Study. OALibJ, 3, 1-15. https://doi.org/10.4236/oalib.1102738

[18] Hem, E., Stokke, G., Tyssen, R., Gronvold, N.T., Vaglum, P. and Ekeberg, O. (2005) Self-Prescribing among Young Norwegian Doctors: A Nine-Year Follow-Up Study of a Nationwide Sample. BMC Medicine, 3, 16.

[19] Soroush, A., Abdi, A., Andayeshgar, B., Vahdat, A. and Khatony, A. (2018) Exploring the Perceived Factors That Affect Self-Medication among Nursing Students: A 
Qualitative Study. BMC Nursing, 17, 35. https://doi.org/10.1186/s12912-018-0302-2

[20] Kumar, A., Khuwaja, A.K. and Khuwaja, A.M. (2012) Knowledge Practice Gaps about Needlestick Injuries among Healthcare Workers at Tertiary Care Hospitals of Pakistan. Journal of Ayub Medical College Abbottabad, 24, 50-52. 